\title{
Effect of Workforce Ethnic Diversity and Education Backgrounddiversity on Employee Performancein Selected Universities in Kenya
}

\author{
Rosemary Muvinya Muange \\ Department of Quantitative Skills and Development Studies, \\ School of Human Resource Development, University of Eldoret, Kenya \\ Ng'etich Willy Kiptoo \\ Department of Quantitative Skills and Development Studies, \\ School of Human Resource Development, University of Eldoret, Kenya
}

\begin{abstract}
The study investigates the effect of workforce ethnic diversity and education background diversity on employee performance in selected universities in Kenya. The objective of the study were to determine the effects of education background diversity on employee performance and to determine the effects of workforce ethnic diversity on employee performance. Social identity theory was used to ground this study. Explanatory research design was adopted, and a survey was conducted on selected Universities in Kenya. Selfadministered questionnaires were distributed to 371 teaching and non-teaching administrators of Universities out of which 305 equal to $82 \%$ of the sample size were returned and were used in data analysis. Cronbach alpha was used to test the reliability of the instruments. Descriptive statistics such as mean, standard deviation and Pearson correlation analysis was done. Regression analysis was done to test the hypotheses and to establish the effect that each variable has on employee performance. The study findings indicate that ethnic diversity $\left(\beta_{1}=0.238, \rho<0.05\right)$, educational diversity $\left(\beta_{2}=0.048, \quad \rho<0.05\right)$ have significant and positive effect on employee performance. This study therefore supports and contributes to the social categorization theory and human resource management literature. The implication is that institutions and firms should consider hiring employees from socially diverse backgrounds to be able to achieve higher employee performance.
\end{abstract}

Keywords:- Workforce Ethnic Diversity, Education Background Diversity, Employee Performance.

\section{INTRODUCTION}

Given the declining success of most companies, the contributions of a diverse workforce can no longer be overemphasized. Higher education institutions and leaders continue to face the opportunities and challenges presented by emerging and increasingly diverse environments. For order to become a successful leader in the area of diversity, university leaders need to be conscious or understand that diversity has an influence on the performance of employees. Nevertheless, this was not the case in any of these organizations (Gipson et al., 2017).
The diversity of the workforce relates to gender, sexual orientation, age, disability, ethnicity, religion, abilities, personality, identity and education. (Saxena, 2014: Zurbrügg, \& Miner, 2016: Sippola, 2014). Despite increased workforce mobility, several businesses have recognized that diversity in the workplace is a challenge. It may cause issues, but it may also become a source of innovation from which employees' abilities develop into business advantages. (Davidsonet al., 2016: Broadbridge \& Fielden, 2018). That is why labor diversity has become a key instrument for satisfaction and performance of employees in both the public and private sectors. Most researchers agree that the elements of labor diversity can have a profound impact on how people respond to each other and how they interpret their commitment to organizational goals.

Wijbenga (2019) proposes that diversity involves primary and secondary dimensions that are critical to the understanding of key (especially primary) factors that contribute to the diversity of the workforce. Primary dimensions are immutable differences that are inborn or represent one's core identity, such as race, ethnicity, gender, age, physical quality / ability, and sexual orientation. These dimensions have a primary influence on the shaping of the individual's self and worldview. Secondary dimensions include educational history, geographical location, income, marital status, religious views and job experience. Such aspects of diversity management are the cornerstone to success in today's intensely competitive global marketplace. In order to gain market relevance in global markets, universities need to embrace diversity-how they think, act and innovate. Both of these factors are responsible for alleged discrimination against employees, whether actual or imaginary, and it is time to tackle them.

Empirical evidence suggests that universities have not made substantial progress in managing team dynamics to reach success expectations for team members that are geographically scattered and culturally diverse (Muethel and Hoegl, 2010). Nor do they seem to have done so from the domestic front, though changes in the world's population create opportunities for people of different cultural backgrounds to work together in diverse 
organizational settings to enhance employee efficiency (Chao and Moon, 2005). In addition, the studies performed by Chao and Moon (2005), Gusoy et al., ( 2008) and Twenge et al., ( 2010) showed that the aging of the population is creating a situation in which the university administration must ensure that multiple generations function in accordance with the performance of workers and the progress of the university.

Although most studies have centered on labor diversity in countries such as Denmark, Australia, the United States and Nigeria, none have been conducted in Kenya in the study area given the country's higher level of diversity. Notwithstanding this, none of them also considered a clear correlation between diversity and the success of workers in the university setting. This study is therefore key to resolving the research gap that currently exists.

\section{$>$ Statement of the Problem}

The workforce in Kenya is increasingly diverse in terms of gender, sex, culture, disability and ethnicity, and senior managers need to consider the effects of this on organizational performance Wambui et al., (2013).

The failure of diversity initiatives in organizations was attributed to a lack of attention to the needs assessment process (Prieto et al., 2009). It is for this reason that the issue whether the educational history or ethnicity of an individual influences some part of his or her success has been examined. Existing research has not given this area the recognition it deserves, in particular, of the possible performance benefits of diversity.

In Kenya, initiatives such as the promulgation of a new constitution and the 'Equality and Freedom from Discrimination' framework, as well as human resources policies in organizations, are moving in the right direction towards diversity, but have remained largely unused. It is considered a matter of law rather than a strategy for achieving the desired organizational objectives .The literature by Richard et al., (2003) recommends an investigation into the potential of a diverse workforce with a competitive advantage for organizations. However, there has been a gap in this area, given that managers have focused more on mentally challenging work, equitable rewards, supportive working conditions and helpful colleagues, without paying more attention to the diversity of the workforce (Luthans et al., 2007). As a result, there has been no systematic structure connecting labor diversity to organizational success in most organizations.

Despite this trend, it is not clear in the context of Kenya whether labor diversity affects organizational performance and, if so, the extent and benefits to universities. Diversity management means the creation of a heterogeneous workforce capable of achieving its capacity in an equal working atmosphere where no member or community of members has an advantage or disadvantage over the other (Garg et al., 2017).
Accordingly, this research aims to extend existing literature on labor diversity by further defining the impact of diversity on the educational history and ethnic composition of the workforce on the performance of employees in selected universities in Kenya.

\section{$>$ Objectives}

- To determine the effect of workforce ethnic diversity on employee performance.

- To establish the effect of diversity in education background and employee performance in an organization.

\section{LITERATURE REVIEW}

\section{$>$ Diversity in Ethnicity}

According to Satter (2014), labor diversity was the hallmark of the 1990s and continued to gain traction in the new age. In addition to the ongoing rise in diversity, there has also been a rise in the use of work teams, with the goal of using greater collaboration and teamwork to enhance and boost both employee satisfaction and efficiency. While the essence of the composition of the workforce is increasingly becoming more diverse in terms of gender, age and ethnicity, there has been an growing interest in the effects of such diversity in our educational institutions (Watson et al., 2002). Multicultural growth in business is due to the multicultural growth of our society and thus also pervades the family, educational and religious circles. Watson et al., (2002) further suggests that variations in cultural characteristics have been predictive of team ratings, which can be interpreted as the benefit of having ethnically diverse perspectives on team problem-solving resulting in improved team success after teams have learned how to use these variations to their benefit.

Innovation has been identified as an interactive process that often involves communication and interaction between employees in a company and draws on their different qualities at all levels of the organization (Østergaard et al., 2011). In other research, the characteristics of diversity, such as ethnic origin, race, gender and age, can have negative impacts on the business. Minority members may experience less job satisfaction, lack of commitment, identity problems, perceived discrimination, etc. (Østergaard et al., 2011; Harrison and Klein, 2007).

According to Lee (2015), ethnicity can be used as a proxy for cultural context and ethnic diversity can be assumed to be positive for creative results. Gupta, (2013), notes that some degree of diversity in ethnicity may be positively correlated with creativity, but that a high degree of diversity in ethnicity may be negative as it may generate tension and clique due to social categorization.

\section{$>$ Diversity in Educational Background}

Educational contexts differ from country to country, depending on the degree of private and public sector involvement in supporting infrastructure. Employers typically avoid hiring staff whose training, experience or 
education is perceived to be insufficient (Arokiasamy, 2013). Employee performance is based on their level of education.

Daniel (2009) also shared this view and went on to point out that different levels and forms of education could be expected to have different mobility rates. For example, occupations that are open to those with work experience but do not have a qualified tertiary or graduation paper can vary from those possessing that level of education. Daniel (2009) further states that, depending on the level of education, the individual will be more productive. The more schooling the individual worker gets, the more successful the worker would be. Moretti (2004) investigated this concept and found that cities with a higher percentage of tertiary education staff would have higher salaries for individuals at all levels of education. Some researchers found a rise in political engagement (Dee, 2004) or a decline in crime rates (Lochner and Moretti, 2004) and an improvement in economic growth (Fanv et al, 2016). This also seems likely that the patterns of thinking under which workers raise their feelings of disappointment and exclusion under conditions of rising diversity will raise and can have significant implications for the dynamics of a diverse community.

\section{$>$ Relationship between Educational Background and Employee Performance}

It is the responsibility of leaders, according to Combs, to implement educational diversity initiatives in an effort to motivate and encourage each individual to work effectively with others in order to achieve organizational goals. The principle of division of labor is intended to promote efficiency in the performance of work. That is why a person's educational history can be a significant predictor of their experience, skills and abilities. According to Elsaid (2012), dissimilarity in educational context tends to have a beneficial effect on team success because it encourages a wider variety of cognitive skills.

Mwatumwa, (2016) contends that the absorption capacity of the organization is likely to increase the variety of knowledge structures as reflected in the various educational majors. Lent, (2002) further argues that the choice of a specific educational institution may represent one's cognitive strength and personality. Bezrukova et al., (2016) noted that informational diversity, such as education and functional areas, was positively related to the actual work group results, although the relationship was mediated by a task conflict. Educational background has also been shown to have a negative impact on team performance and social integration in teams (Elsaid, 2012).

Homberg\&Bui, (2013) found that heterogeneity at the level of education (undergraduate versus graduate) was related to the goal of turnover. Wide differences in educational background have led to an increase in workrelated discussions between work teams (Bezrukova et al., 2007). It seems that heterogeneous educational backgrounds tend to increase the level of discomfort and conflict that can lead to reduced social integration in teams. In other words, education context diversity may have both benefits and drawbacks for the success of employees. Performing the activities that workers have mastered, technically and actually eliminates waste, increases the speed and quality of finished goods.

Ho1 There is no significant relationship between workforce ethnicity and employee performance

\section{$>$ Relationship between Ethnicity and Employee Performance}

Today, public and private companies are more ethnically diverse than ever before. It is therefore important to consider how diversity affects experiences in the workforce and how work-related results improve. According to Dastane, \& Eshegbe, (2015), it is critical that organizations know how to handle their diverse workforce in such a way that they can optimize the benefits of this diversity and reduce its disadvantages. In addition, Pitts and Jarry (2007) argue that organizations are becoming more diverse along ethnic lines and thus make sense to pay more attention to how different groups interact with each other at work. Some researchers have identified ethnic diversity as a source of serious problems, such as communication problems, conflict, discrimination, lack of consensus and lack of cohesion in organizations (Jackson and Joshi, (2004) and Kooij-de Bode et al., (2008).

Despite the obvious problems, scholars have alluded to the fact that ethnic diversity can produce positive results if it is properly managed. According to Opstal (2009), some of the advantages include more creativity, innovation and a larger pool of resources available in the organization (knowledge, skills and social networks). This was supported by Jackson et al., (2004). Managers need to successfully handle diversity in a way that minimizes negative consequences and maximizes benefits (Mwatumwa, 2016).

Richard, (2000) pointed out that diversity in the form of ethnicity can be expected to be positive for innovative performance as it broadens the company's perspectives and perspectives. In addition, based on the Østergaard et al., (2011) study, some levels of ethnic diversity may be positively associated with creativity and improved work performance.

$\mathrm{H}_{02}$ There is no significant relationship between workforce educational background and employee performance 


\section{RESEARCH METHOD}

This study used explanatory research design. The study was conducted in four universities in Kenya. These included; Moi University, Eldoret University, Mount Kenya University and Catholic University of Eastern Africa. The target population for this research included the teaching and administrative employees in the various schools of the target universities

\section{Sample Size Table}

\begin{tabular}{|c|c|c|c|c|}
\hline Institution & Target Population & Population Category & $\begin{array}{c}\text { Population Size Per } \\
\text { Category }\end{array}$ & $\begin{array}{c}\text { Sample size } \\
n=N / 1+N_{e^{2}}\end{array}$ \\
\hline \multirow[t]{2}{*}{ Moi University } & \multirow[t]{2}{*}{1,957} & Teaching & 934 & 79 \\
\hline & & Administrative & 1023 & 87 \\
\hline \multirow[t]{2}{*}{ Mt. Kenya University } & \multirow[t]{2}{*}{1,524} & Teaching & 602 & 51 \\
\hline & & Administrative & 922 & 78 \\
\hline \multirow[t]{2}{*}{ University of Eldoret } & \multirow[t]{2}{*}{363} & Teaching & 56 & 4 \\
\hline & & Administrative & 307 & 26 \\
\hline \multirow[t]{2}{*}{ Catholic University } & \multirow[t]{2}{*}{435} & Teaching & 158 & 13 \\
\hline & & Administrative & 277 & 23 \\
\hline Total & 4,279 & & 4,279 & 371 \\
\hline
\end{tabular}

Table 1

Source: HR Respective Institutions

Taro Yamane (1973) formula was used to calculate sample size from a target population of 4,269. The calculation will be as follows:

Where:

$$
n=N / 1+N_{e^{2}}
$$

$$
\begin{aligned}
& \mathrm{n}=\text { Sample size } \\
& \mathrm{N}=\text { Population size } \\
& \mathrm{e}=\text { the error of Sampling }
\end{aligned}
$$

This study will allow a sampling error of 0.05 .

The calculation yield the following sample size

$371=42691+4269(0.05)^{2}$

The data collected through the questionnaire was analyzed statistically by using the Statistical Package for Social Science (SPSS). The study conducted initial data analysis using descriptive statistics, correlation analysis and regression analysis
The following multiple regression equation was utilized $Y=\alpha+\beta_{1} X_{1}+\beta_{2} X_{2}+\varepsilon$

Where, $\mathrm{Y}=$ employee performance $\alpha=$ Constant

$\beta_{1}$ and $\beta_{2}=$ coefficients of multiple regression model

$\mathrm{X}_{1}=$ Ethnicity

$\mathrm{X}_{2}=$ Educational background

$\varepsilon=$ error term

\section{RESULTS}

\section{* Descriptive Analysis}

Table 2 describes the summary statistics of the responses obtained on the relationship between ethnicity and employee performance. This parameter has a mean

\begin{tabular}{|c|c|c|}
\hline & Mean & Std. Deviation \\
\hline The institution does a good job for attracting and hiring minorities & 4.0033 & .81313 \\
\hline The opportunity for growth and advancement exists for minorities in our institution & 4.0131 & .78209 \\
\hline The institutions concerns about the employees customs, cultures and values & 4.0000 & .73895 \\
\hline At work I develop low self-esteem due to my ethnicity & 3.9377 & .78601 \\
\hline The ethnicity differences in work group do not encourage conflict & 4.0098 & .73666 \\
\hline $\begin{array}{c}\text { The team leader includes all members at different ethnicity in problem solving and decision } \\
\text { making }\end{array}$ & 3.8426 & .88192 \\
\hline I am positive about ethnic diversity in this work place & 3.6984 & 1.00696 \\
\hline Index for ethnicity & 3.9290 & .82082 \\
\hline
\end{tabular}
score of 3.93 and a standard deviation of 0.82082 . This is an indication that the majority of respondents have the same opinion on the relationship between the two variables

Table 2:- Descriptive Statistics for Workforce Ethnicity Management

$\mathbf{N}=305$

*Five point scale: 1 =strongly disagree; $5=$ strongly agree:

Source: Survey Data (2020) 
Descriptive statistics for Educational Background and management

Table 3 below shows that majority of respondents agree that workforce educational background has a significant relationship with employee performance. It has a mean score of 3.8640 and a standard deviation of 0.84506 .

\begin{tabular}{|c|c|c|}
\hline & Mean & Std. Deviation \\
\hline The institution provides paid study leave to employees who further their education & 3.8492 & .80920 \\
\hline $\begin{array}{c}\text { Opportunities for growth and advancement exist for employees who have lower } \\
\text { qualification in education }\end{array}$ & 3.9311 & .82628 \\
\hline At work, I experience lack of confidence due to my education background & 3.8197 & .87562 \\
\hline $\begin{array}{c}\text { The team leader includes all members at different education levels in problem solving and } \\
\text { decision making }\end{array}$ & 3.8557 & .86916 \\
\hline Index for educational background & $\mathbf{3 . 8 6 4 0}$ & $\mathbf{. 8 4 5 0 6}$ \\
\hline
\end{tabular}

Table 3:- Descriptive Statistics for Educational Background and Management

\section{$\mathbf{N}=\mathbf{3 0 5}$}

*Five point scale: $1=$ strongly disagree; $5=$ strongly agree:

Source: Survey Data (2020)

\section{Descriptive statistics for employee performance}

Table 4 shows that majority of respondents in various institutions are of the opinion that employee performance is influenced by workforce diversity at a mean of 4.0290 and a standard deviation of .780453 .

\begin{tabular}{|c|c|c|}
\hline & Mean & Std. Deviation \\
\hline I enjoy my tasks and the divisions work approach & 3.9148 & 1.13813 \\
\hline I am committed to mission and direction of my institution & 4.0492 & .81568 \\
\hline I am motivated to complete the tasks that are assigned to me & 4.1279 & .68348 \\
\hline I cooperate well with my colleagues of different ethnicity & 4.0459 & .78505 \\
\hline opposite gender can perform well and I enjoy working with them & 4.0925 & .75095 \\
\hline My performance level affects my salary level & 4.1246 & .73732 \\
\hline I am satisfied with my work conditions & 3.7344 & .99255 \\
\hline I am given the chance to try my own method of doing the job & 4.0033 & .80907 \\
\hline Bood employee performance is important for the future growth of my institution & 4.1377 & .72142 \\
\hline Index for employee performance & 4.0623 & .37088 \\
\hline Table 4 - Summare & $\mathbf{4 . 7 8 0 4 5 3}$ \\
\hline
\end{tabular}

Table 4:- Summary for Mean and Standard Deviation for Employee Performance

\section{$\mathrm{N}=305$}

*Five point scale: 1 =strongly disagree; $5=$ strongly agree:

Source: Survey Data (2020)

* Correlation Analysis

\begin{tabular}{|c|c|c|c|}
\hline Items & $\mathrm{EP}$ & ETH & $\mathrm{EB}$ \\
\hline EP & 1 & & \\
\hline ETH & $.630^{* 4}$ & 1 & \\
\hline EB & $.589^{4 *}$ & $.655^{4 *}$ & 1 \\
\hline
\end{tabular}

Table 5:- Correlation Results for Test Items

$\mathrm{EP}=$ Employee performance, $\mathrm{ETH}=$ Ethnic diversity, EB=Educational background,

**Correlation is significant at the 0.01 level (2- tailed)

Source: survey Data (2020) 
All the independent variables have positive correlations with the dependent variable, ethnic diversity with coefficients of $(\mathrm{ETH}=0.0630, \mathrm{p}<0.01)$, and educational background had correlation of $(\mathrm{EB}=0.589, \mathrm{P}<0.01)$. This however indicates that all the variables under consideration are statistically significant at $95 \%$ confidence interval level of 2-tailed.This shows that all the variables have a positive effect on the dependent variable.

\begin{tabular}{llcccc}
\hline $\begin{array}{l}\text { Predictor } \\
\text { Variables }\end{array}$ & $\beta$ & \multicolumn{2}{c}{ Tolerance } & VIF \\
\hline & & & & & \\
ETH & .245 & 4.366 & .000 & .470 & 2.126 \\
EB & .054 & .896 & .000 & .417 & 2.401 \\
\hline
\end{tabular}

Dependent variable is Employee Performance $=93.209 ; \mathrm{P}<000 ; \mathrm{R}^{2}=\mathbf{0 . 5 5 4}$; Adjusted $\mathrm{R}^{2}=\mathbf{0 . 5 4 8}$

Source: Survey data (2020)

Table 6:- Regression Analysis

\section{Hypotheses Testing For the Dependent Variable}

The study tested two formulated hypotheses setting significance level at 0.05 , at $95 \%$ confidence interval. The beta coefficients of the study show the slope that explains the relationship between dependent and independent variables. It also shows the coefficient size and magnitude of influence. In addition, $t$-tests were done to compare the beta coefficients with 0 . In this study, standardized coefficients were used to explain the hypotheses results.

To test the hypotheses, the researcher started with the regression between workforce Ethnic diversity, Educational background diversity and employee performance. The contributions of each set of variables were evaluated by determining the significance of the $F$-value associated with the change in Adjusted $\mathrm{R}^{2}$ after each was introduced as proposed by Cagliano et al., 2006)

Hypothesis Ho1: There is no significant effect of diversity in ethnicity on employee performance.
Hypotheses $\mathrm{HO}_{1}$ states that employee ethnicity has no significant effect on employee performance. Results in table 5 indicates that ethnic diversity has coefficient estimates of $(\beta=0.245, p<0.000, t=4.366)$. Since the $p$-value is less than (0.05), the null Hypothesis is rejected. This implies that at $95 \%$ confidence interval ethnic diversity does influence employee performance.

Hypothesis Ho2: There is no significant effect of diversity in educational background on employee performance

Hypotheses $\mathrm{Ho}_{2}$ states that employee educational background has no significant effect on employee performance, but the results in table 5 indicates that workforce ethnicity has coefficients estimate of $(\beta=0.054$, $p<0.000, \mathrm{t}=0.896)$ which is higher than $(\alpha=0.05)$. This implies that at $95 \%$ confidence interval workforce educational background does influence organizational performance, hence null hypotheses is rejected.

\section{Test of Hypotheses Results}

\begin{tabular}{|c|c|c|c|c|}
\hline & Hypothesis & Beta & p-values & Results \\
\hline Ho1: & There is no significant relationship between workforce ethnicity & .245 & $.000^{* *}$ & Reject \\
\hline and employee performance. & $\begin{array}{c}\text { There is no significant relationship between workforce } \\
\text { educational background and employee performance. }\end{array}$ & .054 & $.000^{* *}$ & Reject \\
\hline
\end{tabular}

\section{Table 7}

Note, significance at $p^{* *<0.01, p^{*}<0.05}$

Source survey Data (2020)

From the preceding discussion, it is concluded that the null hypotheses in this study remain rejected as the alternative is supported.

\section{CONCLUSION}

The findings of this study show that high workplace performance has a positive impact on factors such as race and education in universities and other organisations. Companies should address these demographic categories in order to stay competitive.

This study is supported by Bär et al., (2007) a study that based the diversity dimension on a positive relationship to performance. It is also suggested that diverse education and tenure teams outperform teams that are less diverse. The combination of managers and employees with different backgrounds in education, as well as experienced managers and managers who have just entered the industry seems to be an optimal combination to deliver superior performance. The research also points to the fact that teams consisting of members who differ in terms of their tenure know different groups of people, have different technical skills and have a different perspective on the culture and history of the organization. This will provide employees with a wider range of contacts and knowledge and thus improve decision quality and individual performance. 


\section{RECOMMENDATIONS}

The present study shows that companies are most likely to achieve high employee output when the heterogeneous workforce is properly established. This is reflected in efforts made by some organizations to harness ethnic diversity. The linear effects for these characteristics are consistent with the self-categorization view. Hogg et al., (2017), avers that categorization clarifies intergroup boundaries by producing group stereotypical and normative perceptions, and assigns people including self, to the contextually relevant category. It specifies the operation of the social categorization process as the cognitive basis of group behavior.

The educational background diversity has presented different viewpoints. More specifically there has been a fixed mind that the lower the levels of education, the lesser creative employees are. However, it has been established that the level of education alone cannot restrict imaginative solutions, creativity and innovation. None the less Theoretical evidence in favour of this argument is yet to be fully exploited. This study has served to highlight the fact that employee performance is pecked on their level of education. This implies that educational background is important for both employment and effectiveness (Daniel 2009).

The findings of this study are quite valuable since they provide managerial insights on how employee performance may better be harnessed. The implication is that the leadership of organizations should consider aligning employee demographic characteristics with their performance. Diverse workforce is more prepared to process information within their environments due to their evaluative capabilities.

\section{Implications for Further Research}

The study points out that in the Kenyan context, diversity in the service industry should be incorporated into the strategies of the organization for higher employee performance and growth. The development and empirical testing of mediation effects will likely shade more light on the strength of the relationships and effects.

\section{REFFERENCES}

[1]. Arokiasamy, A. R. A. (2013). Literature review on workforce diversity, employee performance and organizational goals: A concept paper. Researchers World, 4(4), 58.

[2]. Bär, M., Niessen-Ruenzi, A., \&Ruenzi, S. (2007). The impact of work group diversity on performance: Large sample evidence from the mutual fund industry. Available at SSRN 1017803.

[3]. Bezrukova, K., Spell, C. S., Perry, J. L., \&Jehn, K. A. (2016). A meta-analytical integration of over 40 years of research on diversity training evaluation. Psychological Bulletin, 142(11), 1227.

[4]. Bezrukova, K., Thatcher, S. M., \&Jehn, K. A. (2007). Group heterogeneity and faultlines: omparing alignment and dispersion theories of group composition. Conflict in organizational groups: New directions in theory and practice, 57-92.

[5]. Boliver, V. (2013). How fair is access to more prestigious UK universities?. The British journal of sociology, 64(2), 344-364.

[6]. Broadbridge, A. M., \&Fielden, S. L. (2018). Research handbook of diversity and careers. Edward Elgar Publishing.

[7]. Chao, G. T., \& Moon, H. (2005). The cultural mosaic: A metatheory for understanding the complexity of culture. Journal of Applied Psychology, 90(6), 1128.

[8]. Cogliano, V. J. (2006). Use of carcinogenicity bioassays in the IARC monographs. Annals of the New York Academy of Sciences, 1076(1), 592-600.

[9]. Combs, G. M. (2002). Meeting the leadership challenge of a diverse and pluralistic workplace: Implications of self-efficacy for diversity training. Journal of Leadership Studies, 8(4), 1- 16.

[10]. Daniel C.H. (2009). The effects of higher education policy on the location decision of individuals: Evidence from Florida's Bright Futures Scholarship Program. Regional Science and Urban Economics, 39, 553- 562.

[11]. Dastane, O., \&Eshegbe, J. W. (2015). Effect of diversity elements at workplace: An empirical study. International Journal of Accounting and Business Management, 3(1), 62-69.

[12]. Davidson, M. J., \& Burke, R. J. (2016). Women in management worldwide: Progress and prospects-An overview. In Women in Management Worldwide (pp. 19-36). Gower.

[13]. Dee, T.S. (2004). Are there civic returns to education? Journal of Public Economics, 88(9-10), 1697-1720.

[14]. Elsaid, A. M. (2012). The effects of cross cultural work force diversity on employee performance in Egyptian pharmaceutical organizations. Business and Management Research, 1(4), 162.

[15]. Fan, Q., Goetz, S. J., \& Liang, J. (2016). The interactive effects of human capital and quality of life on economic growth. Applied Economics, 48(53), 5186-5200.

[16]. Garg, S., Pandey, D. K., \&Vashishta, A. (2017). Workforce diversity management techniques. ZENITH International Journal of Business Economics \& Management Research, 7(4), 41-46.

[17]. Gipson, A. N., Pfaff, D. L., Mendelsohn, D. B., Catenacci, L. T., \& Burke, W. W. (2017). Women and leadership: Selection, development, leadership style, and performance. The Journal of Applied Behavioral Science, 53(1), 32-65.

[18]. Gupta, R. (2013). Workforce diversity and organizational performance. International Journal of Business and Management Invention, 2(6), 36-41.

[19]. Gursoy, D., Maier, T. A., \& Chi, C. G. (2008). Generational differences: An examination of work values and generational gaps in the hospitality workforce. International Journal of Hospitality Management, 27(3), 448-458. 
[20]. Harrison, D. A., \& Klein, K. J. (2007). What's the difference? Diversity constructs as separation, variety, or disparity in organizations. Academy of management review, 32(4), 1199-1228.

[21]. Hickman, D. C. (2009). The effects of higher education policy on the location decision of individuals: Evidence from Florida's Bright Futures Scholarship Program. Regional science and urban Economics, 39(5), 553-562.

[22]. Hogg, M. A., Abrams, D., \& Brewer, M. B. (2017). Social identity: The role of self in group processes and intergroup relations. Group Processes \& Intergroup Relations, 20(5), 570581.

[23]. Homberg, F., \& Bui, H. T. (2013). Top management team diversity: A systematic review. Group \& Organization Management, 38(4), 455-479.

[24]. Jackson, S. E., \& Joshi, A. (2004). Diversity in social context: a multi-attribute, multilevel analysis of team diversity and sales performance. Journal of Organizational Behavior: The International Journal of Industrial, Occupational and Organizational Psychology and Behavior, 25(6), 675702.

[25]. Kooij-de Bode, H. J., van Knippenberg, D., \& van Ginkel, W. P. (2008). Ethnic diversity and distributed information in group decision making: The importance of information elaboration. Group Dynamics: Theory, Research, and Practice, 12(4), 307.

[26]. Lee, N. (2015). Migrant and ethnic diversity, cities and innovation: Firm effects or city effects?. Journal of Economic Geography, 15(4), 769-796.

[27]. Lent, R. W., Brown, S. D., \& Hackett, G. (2002). Social cognitive career theory. Career choice and development, 4, 255-311.

[28]. Lochner, L., \&Moretti, E. (2004). The effect of education on crime: Evidence from prison inmates, arrests, and self-reports. American economic review, 94(1), 155-189.

[29]. Luthans, F., Youssef, C. M., \&Avolio, B. J. (2007). Psychological capital: Developing the human competitive edge.

[30]. Moretti, E. (2004). Estimating the social return to higher education: evidence from longitudinal and repeated cross-sectional data. Journal ofEconometrics, $121,175-212$.

[31]. Muethel, M., \&Hoegl, M. (2010). Cultural and societal influences on shared leadership in globally dispersed teams. Journal of International Management, 16(3), 234-246.

[32]. Mwatumwa, A. S. (2016). Effect of workforce diversity on employee work performance: a study of the county government of Mombasa.

[33]. Nielsen, S. (2009). Why do top management teams look the way they do? A multilevel exploration of the antecedents of TMT heterogeneity. Strategic Organization, 7(3), 277-305.

[34]. Opstal, E. V. (2009). Management diversity. The relationship between the management of ethnic cultural, 3, 25-46.
[35]. Østergaard, C. R., Timmermans, B., \&Kristinsson, K. (2011). Does a different view create something new? The effect of employee diversity on innovation. Research Policy, 40(3), 500-509.

[36]. Pitts, D., \&Jarry, E. (2007). Ethnic diversity and organizational performance: Assessing diversity effects at the managerial and street levels. International Public Management Journal, 10(2), 233-254.

[37]. Prieto, L. C., Phipps, S. T., \&Osiri, J. K. (2009). Linking workplace diversity to organizational performance: A conceptual framework. Journal of Diversity Management (JDM), 4(4), 13- 22.

[38]. Richard, O. C. (2000). Racial diversity, business strategy, and firm performance: A resource-based view. Academy of management journal, 43(2), 164177.

[39]. Richard, O., McMillan, A., Chadwick, K., \& Dwyer, S. (2003). Employing an innovation strategy in racially diverse workforces: Effects on firm performance. Group \& Organization Management, 28(1), 107-126.

[40]. Satter, S. B. (2014). Sustaining a mature teacher inquiry network (Doctoral dissertation, Boston University).

[41]. Saxena, A. (2014). Workforce diversity: A key to improve productivity. Procedia Economics and Finance, 11(1), 76-85.

[42]. Sippola, A. (2014). Essays on human resource management perspectives on diversity management. Vaasanyliopisto.

[43]. Twenge, J. M., Gentile, B., DeWall, C. N., Ma, D., Lacefield, K., \&Schurtz, D. R. (2010). Birth cohort increases in psychopathology among young Americans, 1938-2007: A cross- temporal meta-analysis of the MMPI. Clinical psychology review, 30(2), 145-154.

[44]. Van Dick, R., Van Knippenberg, D., Hägele, S., Guillaume, Y. R., \&Brodbeck, F. C. (2008). Group diversity and group identification: The moderating role of diversity beliefs. Human Relations, 61(10), 1463-1492.

[45]. Wambui, T. W., Wangombe, J. G., Muthura, M. W., Kamau, A. W., \& Jackson, S. M. (2013). Managing workplace diversity: A Kenyan perspective. International Journal of Business and Social Science, 4(16), 199-218.

[46]. Watson, W. E., Johnson, L., \&Zgourides, G. D. (2002). The influence of ethnic diversity on leadership, group process, and performance: An examination of learning teams. International Journal of Intercultural Relations, 26(1), 1-16.

[47]. Wijbenga, H. M. (2019). Workplace diversity in the Netherlands, its governing and an examination of the relation to workplace conflicts (Doctoral dissertation).

[48]. Zurbrügg, L., \& Miner, K. N. (2016). Gender, sexual orientation, and workplace incivility: Who is most targeted and who is most harmed?. Frontiers in psychology, 7, 565. 